\title{
Atlas of histopathology
}

\section{Luciano Pasini, MIAC}

Responsabile, Servizio di Patologia Clinica, Casa di Cura "Giovanni XXIII", Monastier di Treviso

Ricevuto: 14 marzo 2012 / Accettato: 14 marzo 2012

(C) Springer 2012

\section{Ivan Damjanov}

Atlas of Histopathology

Jaypee Brothers Medical Publishers (P) LTD, 2012, pagine 393

ISBN 978-93-5025-188-1

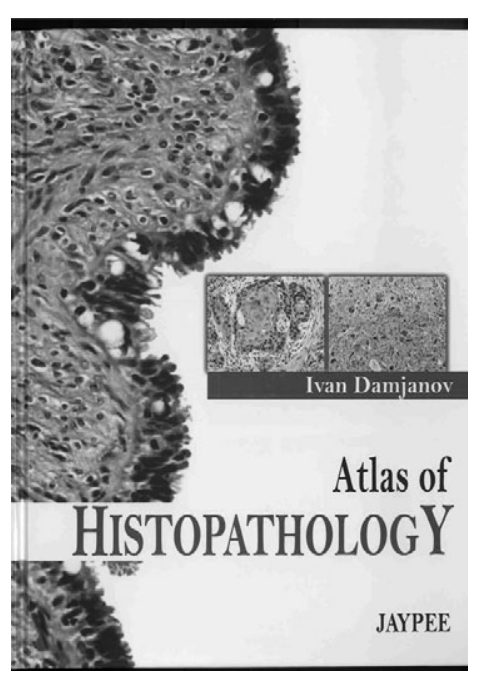

Le note della quarta di copertina danno la chiave di lettura di un lavoro dedicato alla formazione degli studenti e dei giovani specializzandi, collocato tra la patologia generale e l'istopatologia diagnostica. La divisione è schematica, il testo essenziale, ma non povero, con annotazioni che aiutano alla strutturazione mentale di approccio alla patologia nelle sue linee portanti, senza caricarle di nozioni su lesioni rare che andranno acquisite in un momento successivo, quando lo studente deciderà di affrontare la professione di patologo.

L'introduzione ai singoli capitoli è stringata con riferimenti alla fisiologia e all'anatomia macroscopica e microscopica. La patologia dei singoli organi è suddivisa solitamente tra anomalie delle sviluppo, infezioni e neoplasie con le peculiarità proprie delle lesioni più frequenti, riferimenti agli agenti etiologici più importanti, focali accenni alle prognosi.

L'iconografia è splendida, nitida, chiara, volutamente essenziale. Le didascalie alle immagini connotano le lesioni in modo inequivocabile. I richiami alle colorazioni ancillari e alle indagini immunoistochimiche sono ridotte alla estrema sintesi di necessità. Mancano le usuali indicazioni degli ingrandimenti alle microfotografie. Sicuramente il volume soddisfa le aspettative per cui è stato allestito perché è chiaro, essenziale, formativo e un sicuro ponte per avvicinarsi alla microscopia istopatologica. 